\title{
Gut microeukaryotes during anorexia nervosa: a case report
}

Nina Gouba ${ }^{1,2}$, Didier Raoult ${ }^{1,2}$ and Michel Drancourt ${ }^{1,2^{*}}$

\begin{abstract}
Background: Few studies have focused on eukaryote community in the human gut. Here, the diversity of microeukaryotes in the gut microbiota of an anorexic patient was investigated using molecular and culture approaches.

Case presentation: A 21-year-old Caucasian woman was admitted in an intensive care unit for severe malnutrition in anorexia nervosa. One stool specimen was collected from the anorexic patient, culture and polymerase chain reaction-based explorations yielded a restricted diversity of fungi but four microeukaryotes Tetratrichomonas sp., Aspergillus ruber, Penicillium solitum and Cladosporium bruhnei previously undescribed in the human gut.
\end{abstract}

Conclusions: Establishing microeukaryote repertoire in gut microbiota contributes to the understanding of its role in human health.

Keywords: Anorexia nervosa, Gut, Microeukaryotes, Polymerase chain reaction, Culture

\section{Background}

Few studies have focused on the diversity of microeukaryotes and eukaryotes in the human gut of standard weight and obese individuals. The investigation using molecular methods approaches reported an increased fungal burden in patients with Crohn's disease, hepatitis B, inflammatory bowel disease and intestinal transplanted patients compared to healthy individuals [1]. The aim of this study was to make a comprehensive analysis of eukaryote communities in the gut of an anorexic human using both polymerase chain reaction -sequencing and culture techniques.

\section{Case presentation}

A 21-year-old Caucasian woman living in Marseille, France, weighing $27.7 \mathrm{~kg}$ and measuring $1.63 \mathrm{~m}$ with a $10.4 \mathrm{~kg} / \mathrm{m}^{2}$ body mass index (BMI) was admitted to the intensive care unit. The patient suffered from a severe form of anorexia nervosa with severe malnutrition. The investigation of patient dietary habits indicated that she usually drank tea, nonfat milk and fruit juice; ate cereals, a piece of bread and a few fruits for breakfast. For lunch or dinner, she ate vegetables, like zucchini, carrots and beans,

\footnotetext{
* Correspondence: michel.drancourt@univmed.fr

'Aix Marseille Université, URMITE, UMR63, CNRS 7278, IRD 198, Inserm 1095, Marseille 13005, France

${ }^{2}$ Unité de Recherche sur les Maladies Infectieuses et Tropicales Emergentes, Faculté de Médecine, 27, Boulevard Jean Moulin, Marseille cedex 5, France
}

few noodles, rice or grilled bread, fish, turkey, vegetarian steaks, nuts, milk products. She regularly drank tea and fruit juices. She flavored meals with cinnamon, fennel seeds, curry and brewer's yeast. The patient provided her written consent to participate in the present study. The agreement of the local ethics committee of the Institut Fédératif de Recherche 48 was obtained for this study (Agreement number 09-022, Marseille, France). One stool sample collected aseptically the first day of hospitalization was preserved as $1 \mathrm{~g}$ aliquots in sterile microtubes stored at $-80^{\circ} \mathrm{C}$ until use. The patient had no antibiotic or antifungal treatment during the month prior to the stool collection.

Before being used, the deoxyribonucleic acid (DNA) extracted using the Qiamp ${ }^{\circ}$ stool mini kit (Qiagen, Courtaboeuf, France) as previously described, was stored at $-20^{\circ} \mathrm{C}$ [2]. A set of 35 eukaryotic polymerase chain reaction (PCR) primer pairs retrieved from the literature were used to amplify the $18 \mathrm{~S}$ ribosomal ribonucleic acid (rRNA) gene and the internal transcribed spacer (ITS rRNA) of fungi, protozoa, helminthes, arthropods and plants (Table 1) [2]. Potential stool PCR inhibitors were tested by mixing Acanthamoeba castellanii DNA with DNA from stool specimen prior to PCR, as previously described [2]. Distilled water was used as negative control in all PCR reactions. PCRs were performed using the 2720 
Table 1 Ten eukaryotic primers used in complement with those reported in a previous study [2]

\begin{tabular}{|c|c|c|c|c|c|}
\hline Taxon & Primer & Target & $\begin{array}{l}\text { PCR product } \\
\text { size (bp) }\end{array}$ & $\begin{array}{c}\text { Annealing } \\
\text { temperature }\left({ }^{\circ} \mathrm{C}\right)\end{array}$ & Reference \\
\hline \multirow[t]{2}{*}{ Helminthes } & $\mathrm{NC1} / \mathrm{NC2}$ & 18S rRNA gene & $310-410$ & 55 & {$[3]$} \\
\hline & TDR5/TDR3 & & 1700 & 57 & {$[3]$} \\
\hline Blastocystis spp. & $\mathrm{SF} / \mathrm{SR}$ & 18S rRNA gene & 600 & 55 & {$[4]$} \\
\hline \multirow[t]{2}{*}{ Plasmodium spp. } & PLAS1/PLAS2 & Cytochrome b gene & 709 & 55 & {$[5]$} \\
\hline & PLAS3/PLAS4 & & 709 & 55 & [5] \\
\hline Plant & rD5-ITS2/rb1-ITS2f & ITS-2 gene & 350 & 59 & [6] \\
\hline \multirow[t]{2}{*}{ Arthropoda } & ZBJ-ArtF1c/ZBJ-ArtR2C & Mitochondrial coxl gene & 157 & $56-57$ & [7] \\
\hline & CB3/CB4 & Cytochrome b gene & 410 & 46 & {$[8]$} \\
\hline \multirow[t]{2}{*}{ Leishmania spp. } & LeF/LeR & 18S rRNA gene & 330 & 65 & [9] \\
\hline & LEI70R/LEI70L & & & 65 & [9] \\
\hline
\end{tabular}

thermal cycler (Applied Biosystems, Saint Aubin, France). PCR products purified using the Nucleo- Fast ${ }^{\oplus} 96$ PCR Kit (Marcherey-Nagel, Hoerdt, France) were cloned separately using the pGEM $^{\oplus}$-T Easy Vector System Kit (Promega, Lyon, France). PCR amplification using M13 forward (5'-GTAAAACGACGGCCAG-3') and M13 reverse (5'-AG GAAACAGCTATGAC-3') primers (Eurogentec, Seraing, Belgium) were performed on white colonies to confirm the presence of the insert. Purified PCR products were sequenced using M13 primers and the Big Dye ${ }^{\odot}$ Terminator V1.1 Cycle Sequencing Kit on ABI PRISM 3130 automated sequencer (Applied Biosystems). Sequences were compared with those available in GenBank database using basic local alignment search tool (BLAST). Seven of 35 (20\%) pairs yielded a PCR product with the stool specimen as did control A. castellanii DNA. The analysis of 348 clones identified 28 eukaryotic species consisting of 17 (61\%) Viridiplantae species, eight (29\%) fungi S. cerevisiae, $P$. solitum, C. bruhnei, C. capitatum, Sclerotium sp., $M$. pachydermatis, $M$. restricta and $M$. globosa; two metazoa $M$. trossulus and M. galloprovincialis and one protozoan Tetratrichomonas spp. (Table 2). Original sequences here reported have been deposited in GenBank database with accession numbers from JX132667 to JX133078.

In addition, one gram of stool was diluted in $9 \mathrm{~mL}$ sterile phosphate-buffered saline and then spread in duplicate on potato dextrose agar (PDA) (Sigma-Aldrich, Saint-Quentin Fallavier, France), Czapeck dox agar (SigmaAldrich) supplemented with $0.05 \mathrm{~g} / \mathrm{L}$ chloramphenicol and $0.1 \mathrm{~g} / \mathrm{L}$ gentamycin and Dixon agar supplemented with $0.05 \mathrm{mg} / \mathrm{mL}$ chloramphenicol and $0.2 \mathrm{mg} / \mathrm{mL}$ cycloheximide [2]. Plates were incubated aerobically at room temperature $\left(\sim 25^{\circ} \mathrm{C}\right)$ in the dark, except for Dixon agar plates, which were incubated aerobically at $30^{\circ} \mathrm{C}$. The phosphate-buffered saline solution was spread on the same media and incubated in the same conditions as negative controls. Growth was observed for two weeks.
DNA extracted from colonies as described above was amplified with the fungal primers ITS 1 F/ITS 4R. Purified PCR products were sequenced as described above. While negative control plates remained sterile, six fungi including A. ruber, A. flavus, C. capitatum, M. globosa, $M$. restricta and $M$. pachydermatis grew in the two media (Table 3).

\section{Discussion}

Mycological data were certified since negative controls introduced in both PCR- and culture-based observations remained negative. Moreover, four fungi were detected by culture as well as by PCR-sequencing. Combining two methods, a total of ten different fungal species were detected, including S. cerevisiae, A. flavus, M. pachydermatis, $M$. globosa and $M$. restricta previously detected in the stools of healthy individuals and patients; as well as $C$. capitatum and Sclerotium sp. previously detected in intestinal biopsy from inflammatory bowel disease [1]. $A$. ruber, $P$. solitum, C. bruhnei and Tetratrichomonas sp. have not been previously detected in human stool, although Tetratrichomonas sp. has been previously found in the oral cavity and respiratory tract. These organisms have no known pathogenicity in the human gut. Accordingly, $S$. cerevisiae is a commensal fungal in the human gut. However, A. flavus has been reported in the course of gastrointestinal aspergillosis.

The diversity of fungal species observed in this study (ten fungal species) is rather low compared to that observed in our previous study describing an obese patient, where sixteen fungal species have been detected [2]. This supports previous observations that the repertoire of bacterial species differed in anorexic and obese individuals [10]. Other studies also showed a more diverse fungal repertoire in patients than in healthy individuals [1].

Most of eukaryotic species identified in stools in this study were associated with food consumed by the patient. 
Table 2 Polymerase chain reaction results and clone sequencing from the stool specimen collected in this case report

\begin{tabular}{|c|c|c|c|c|c|c|}
\hline Primers & $\begin{array}{c}\text { Total number } \\
\text { of clones }\end{array}$ & $\begin{array}{c}\text { Number of } \\
\text { clones per species }\end{array}$ & Species & $\begin{array}{c}\text { Blast } \\
\text { coverage } \%\end{array}$ & $\begin{array}{l}\text { Blast coverage } \\
\text { identity } \%\end{array}$ & Phylum \\
\hline \multirow[t]{10}{*}{ EUK1A/EUK516r } & 43 & $6 / 43$ & Mytilus trossulus (seefood) & 100 & 99 & Metazoan \\
\hline & & $12 / 43$ & Lycium barbarum (tea) & 100 & 98 & Viridiplantae \\
\hline & & $6 / 43$ & Juglans nigra (nut) & 96 & 99 & Viridiplantae \\
\hline & & $8 / 43$ & Phaseoleae environmental & 100 & 99 & Viridiplantae \\
\hline & & $2 / 43$ & Panax notoginseng (ginger) & 100 & 99 & Viridiplantae \\
\hline & & $2 / 43$ & Fallopia japonica (infusion) & 100 & 99 & Viridiplantae \\
\hline & & $3 / 43$ & Angelica gigas (infusion) & 99 & 99 & Viridiplantae \\
\hline & & $2 / 43$ & Humulus lupulus & 100 & 98 & Viridiplantae \\
\hline & & $1 / 43$ & Grevillea robusta & 99 & 98 & Viridiplantae \\
\hline & & $1 / 43$ & Atractylodes japonica & 100 & 99 & Viridiplantae \\
\hline \multirow[t]{7}{*}{ JVF/DSPR2 } & 60 & $24 / 60$ & Lycium barbarum & 99 & 98 & Viridiplantae \\
\hline & & $9 / 60$ & Prunus persica (fruit) & 96 & 99 & Viridiplantae \\
\hline & & $14 / 60$ & Phaseoleae environmental & 99 & 99 & Viridiplantae \\
\hline & & $5 / 60$ & Carya glabra (nut) & 96 & 99 & Viridiplantae \\
\hline & & $2 / 60$ & Saccharomyces cerevisiae & 100 & 99 & Fungi \\
\hline & & $1 / 60$ & Laurus nobilis culinaire & 99 & 99 & Viridiplantae \\
\hline & & $5 / 60$ & Mytilus galloprovincialis (seefood) & 99 & 99 & Metazoan \\
\hline \multirow[t]{2}{*}{ TFR1/TFR2 } & 25 & $15 / 25$ & Tetratrichomonas sp. & 100 & 100 & Protozoan \\
\hline & & $10 / 25$ & Humulus lupulus & 100 & 98 & Viridiplantae \\
\hline \multirow[t]{4}{*}{ MalF/MalR } & 56 & $34 / 56$ & Malassezia pachydermatis & 100 & 93 & Fungi \\
\hline & & $12 / 56$ & Malassezia restricta & 100 & 99 & Fungi \\
\hline & & $6 / 56$ & Malassezia globosa & 100 & 99 & Fungi \\
\hline & & $4 / 56$ & Cystofilobasidium capitatum & 100 & 99 & Fungi \\
\hline \multirow[t]{4}{*}{ CUF/CUR } & 52 & $20 / 52$ & Trigonella foenum-graecummecinal (vegetables) & 100 & 99 & Viridiplantae \\
\hline & & $8 / 52$ & Juglans regia (nut) & 100 & 99 & Viridiplantae \\
\hline & & $19 / 52$ & Foeniculum vulgare (vegetables) & 100 & 99 & Viridiplantae \\
\hline & & $5 / 52$ & Convolvulus arvensis (tea) & 100 & 99 & Viridiplantae \\
\hline \multirow[t]{5}{*}{ FunF/FunR } & 42 & $9 / 42$ & Dryas octopetala (tea) & 99 & 99 & Viridiplantae \\
\hline & & $5 / 42$ & Penicillium solitum & 99 & 99 & Fungi \\
\hline & & $4 / 42$ & Cladosporium bruhnei & 100 & 99 & Fungi \\
\hline & & $2 / 42$ & Prunus persica (fruit) & 99 & 98 & Viridiplantae \\
\hline & & $22 / 42$ & Sclerotium sp. & 94 & 99 & Fungi \\
\hline rD5-ITS2/rb1-ITS2 & 70 & $70 / 70$ & Palaquium formosanum & 100 & 93 & Viridiplantae \\
\hline
\end{tabular}

A. ruber and A. flavus have been described in cereals and in human oral mycobiome. P. solitum and C. bruhnei were previously described on the surface of fruits and $S$. cerevisiae is used in beer brewing process. Also, M. trossulus and M. galloprovincial are the seafood species which are reported for the first time in the human gut in this report. Moreover, 15/17 (88\%) plants that were detected from the patient's gut could be linked to the food being consumed by the patient including edible nuts (Juglans nigra, Juglans regia, Carya glabra), herbal teas (Angelica gigas, Dryas octopetala, Panax notoginseng, Convolvulus arvensis) or infusions (Lycium barbarum), vegetables (Trigonella foenum-graecum, Foeniculum vulgare, Fallopia japonica, Laurus nobilis and Phaseolea environmental) and fruits (Prunus persica). Humulus lupulus is a hop, which is used in the brewing industry. The herbal teas have medical interest being used to treat gastritis and as antiinflammation agents. The nuts are reported to have nutritional value as they are lipid and protein reserves. Similar link between dietary habits and gut microbiota has been 
Table 3 Fungi cultured from stool collected in patient with severe malnutrition and anorexia nervosa

\begin{tabular}{cccc}
\hline Species & $\begin{array}{c}\text { ITS sequences } \\
\text { blast coverage } \%\end{array}$ & $\begin{array}{c}\text { ITS sequences } \\
\text { blast identity \% }\end{array}$ & $\begin{array}{c}\text { Culture } \\
\text { media }\end{array}$ \\
\hline Aspergillus ruber & 99 & 100 & $\begin{array}{c}\text { Potato } \\
\text { dextrose agar }\end{array}$ \\
$\begin{array}{c}\text { Aspergillus flavus } \\
\text { Cystofilobasidium } \\
\text { capitatum }\end{array}$ & 100 & 100 & $\begin{array}{c}\text { Potato } \\
\text { dextrose agar } \\
\text { Dixon agar }\end{array}$ \\
$\begin{array}{c}\text { Malassezia globosa } \\
\text { Malassezia restricta }\end{array}$ & 100 & 99 & Dixon agar \\
Malassezia & 100 & 99 & Dixon agar \\
pachydermatis & 100 & 99 & Dixon agar \\
& & 94 & Dixon agar \\
\hline
\end{tabular}

made in Malawian twins with kwashiorkor and children in Burkina Faso. Also, Candida and Sacharromyces have been previously found to be associated with diet.

\section{Conclusions}

Here, exploration of microeukaryotes in one stool specimen in patient with severe anorexia, correlated with her dietary and found restrictive diversity in fungi despite the detection of four species previously unreported in the human gut. Establishing the repertoire of microeukaryotes in gut microbiota is necessary to better understand its role in human health.

\section{Consent}

Written informed consent was obtained from the patient for publication of this case report. A copy of the written consent is available for review by the Editor-in-Chief of this journal.

\section{Competing interests}

The authors declare that they have no competing interests.

\section{Authors' contributions}

NG analyzed the stool sample and prepared the manuscript. MD and DR evaluated the draft and suggested revisions. Both authors reviewed and approved the final version of the manuscript.

\section{Acknowledgements}

Nina Gouba benefits a PhD grant from the Foundation Infectiopole Sud. The authors acknowledge the help of Professor Bernard Vialette who provided the information of this case and also Anne Pfleiderer who surveyed the patient's dietary.

Received: 6 September 2013 Accepted: 20 December 2013

Published: 13 January 2014

\section{References}

1. Scanlan PD, Marchesi JR: Micro-eukaryotic diversity of the human distal gut microbiota: qualitative assessment using culture-dependent and -independent analysis of faeces. ISME J 2008, 2:1183-1193.

2. Gouba N, Raoult D, Drancourt M: Plant and fungal diversity in gut microbiota as revealed by molecular and culture investigations. PLOS One 2013, 8:e59474.
3. De Gruijter JM, Van LL, Gasser RB, Verweij JJ, Brienen EA, Ziem JB, Yelifari L, Polderman AM: Polymerase chain reaction-based differential diagnosis of Ancylostoma duodenale and Necator americanus infections in humans in northern Ghana. Trop Med Int Health 2005, 10:574-580.

4. Scicluna SM, Tawari B, Clark CG: DNA barcoding of Blastocystis. Protist 2006, 157:77-85.

5. Duval L, Robert V, Csorba G, Hassanin A, Randrianarivelojosia M, Walston J, Nhim T, Goodman SM, Ariey F: Multiple host-switching of Haemosporidia parasites in bats. Malar J 2007, 6:157-165.

6. Bradley BJ, Stiller M, Doran-Sheehy DM, Harris T, Chapman CA, Vigilant L, Poinar $\mathrm{H}$ : Plant DNA sequences from feces: potential means for assessing diets of wild primates. Am J Primatol 2007, 69:699-705.

7. Pons J: DNA-based identification of preys from non-destructive, total DNA extractions of predators using arthropod universal primers. $\mathrm{Mol}$ Ecol Notes 2006, 6:623-626.

8. Zeale MR, Butlin RK, Barker GL, Lees DC, Jones G: Taxon-specific PCR for DNA barcoding arthropod prey in bat faeces. Mol Ecol Resour 2011, 11:236-244

9. Spanakos G, Piperaki ET, Menounos PG, Tegos N, Flemetakis A, Vakalis NC: Detection and species identification of old world Leishmania in clinical samples using a PCR-based method. Trans R Soc Trop Med Hyg 2008, 102:46-53.

10. Armougom F, Henry M, Vialettes B, Raccah D, Raoult D: Monitoring bacterial community of human gut microbiota reveals an increase in Lactobacillus in obese patients and methanogens in anorexic patients. PLoS One 2009, 4(e7125):491-501.

doi:10.1186/1756-0500-7-33

Cite this article as: Gouba et al.: Gut microeukaryotes during anorexia nervosa: a case report. BMC Research Notes 2014 7:33.

\section{Submit your next manuscript to BioMed Central and take full advantage of:}

- Convenient online submission

- Thorough peer review

- No space constraints or color figure charges

- Immediate publication on acceptance

- Inclusion in PubMed, CAS, Scopus and Google Scholar

- Research which is freely available for redistribution 